\title{
ALIENAÇÃO PARENTAL: A RESPONSABILIZAÇÃO DO ENTE ALIENADOR POR MEIO DA PRÁTICA RESTAURATIVA
}

PARENTAL ALIENATION: THE ALIENATOR'S LIABILITY THROUGH RESTORATIVE PRACTICE

\author{
Rafaella Rodrigues Malta ${ }^{1}$ \\ UFMG \\ Walsir Edson Rodrigues Júnior ${ }^{2}$ \\ PUC Minas
}

\section{Resumo}

O presente trabalho tem como objetivo expor como se configura a alienação parental e como a prática restaurativa de processos circulares se traduz em uma possibilidade legítima, efetiva e transformadora do conflito da alienação parental, visando à reparação dos danos e à responsabilização ativa do ente alienador. A hipótese é que, diante da complexidade desse fenômeno familiar, torna-se possível empregar a prática restaurativa de processos circulares como método autônomo de resolução de conflitos extrajudicial para promover o acesso a uma ordem jurídica justa. Dessa forma, atento se estaria à Doutrina da Proteção Integral da Criança e do Adolescente apregoada na Constituição de 1988 e no Estatuto da Criança e do Adolescente (Lei n. 8.069/90).

Palavras-chaves

Síndrome da Alienação Parental. Alienação Parental. Parentalidade. Conjugalidade. Acesso material à justiça. Prática restaurativa. Processos Circulares.

\begin{abstract}
This paper aims at explaining how parental alienation is configured and how restorative practice of circular processes result in a legitimate, effective and transformative possibility to the parental alienation conflict, in order to repair damages and actively blame the alienator The bypothesis is: given the complexity of this familiar phenomenon, it is possible to apply restorative practice of circle processes as an extrajudicial autonomous dispute resolution method to promote access to fair legal system. Thus, in this way, attention to the Integral Protection Doctrine of Children and Adolescents, proclaimed at the 1988 Constitution and to the Child and Adolescent Statute (n. 8.069/90) is given.
\end{abstract}

Keywords

\footnotetext{
${ }^{1}$ Mestranda em Direito pela UFMG

${ }^{2}$ Professor do Programa de Pós-graduação em Direito da PUC Minas.
} 
Parental Alienation Syndrome. Parental Alienation. Parenting. Conjugality. Material access to justice. Restorative practice. Circle processes.

\section{INTRODUÇÃO}

Como bem preceitua o art. $3^{\circ}$ da Lei $n^{\circ} 12.318 / 2010$, a alienação parental fere direito fundamental da criança ou do adolescente à convivência familiar saudável, "prejudica a realização de afeto nas relações com genitor e com o grupo familiar, constitui abuso moral contra a criança ou o adolescente e descumprimento dos deveres inerentes à autoridade parental ou decorrentes de tutela ou guarda.". Nota-se que é um assunto extremamente relevante e muito delicado, uma vez que se trata de abuso emocional grave.

A alienação parental pode causar lesões e sequelas mais gravosas que de outros tipos de abuso, como o de cunho sexual, por exemplo (GARDNER, 2002). Entretanto, observa-se que para o ente alienador seu comportamento é exemplar, pois conjectura com a hipótese de estar protegendo a criança ou o adolescente do outro genitor. Nesses casos, o contrassenso reside no fato de que o ofensor não percebe que está agredindo a criança ou adolescente que esteja sob sua autoridade parental, guarda ou vigilância.

Comumente a alienação parental surge num contexto de dissolução da relação conjugal ou de companheirismo havido entre os pais dessa criança ou adolescente. Nesse ambiente, diversos são os casos de ocorrência de conflitos familiares que refletem uma tormentosa lide psicológica. Não raro, o ente alienador carrega angústias e rancor acerca daquele cuja imagem passa a ser constantemente denegrida.

Perante a complexidade desse conflito familiar, percebe-se que uma decisão judicial provavelmente não será capaz de (re)estabelecer um ambiente de convivência familiar saudável. Do contrário; ante à formalidade regente do provimento jurisdicional heterônomo, uma decisão não suficientemente atenta aos aspectos psicológicos presentes no caso irá potencializar o conflito já preexistente. Nesse diapasão, mostra-se mais adequado propor às partes conflitantes métodos autônomos de resolução de conflito. 


\section{Revista da Faculdade Mineira de Direito $\mid$ V.20 N.40|247}

Diante da vastidão do tema, delimitaram-se dois eixos de abordagem neste trabalho: um que conceitua a alienação parental e trata do contexto majoritário em que este conflito tende a surgir, e outro que analisa criticamente as hipóteses de responsabilização do ente alienador expressas no ordenamento jurídico brasileiro e assinala uma possível saída apta à transformação do conflito (LEDERACH, 2003).

\section{O EXERCÍCIO DA AUTORIDADE PARENTAL E A DISSOLUÇÃO DO VÍNCULO FAMILIAR ENTRE OS GENITORES}

Sabe-se que a autoridade parental subsiste em razão do elo de filiação com cada um dos genitores, independente de haver entre estes algum vínculo familiar, conforme disposto no art. 1.632, CC/2002 (ALMEIDA; RODRIGUES JR., 2012, p. 450). Contudo, parece inevitável que a dissolução do vínculo familiar entre os genitores impacte o exercício da autoridade parental sobre os seus filhos.

A autoridade parental, também chamada de poder familiar, é a prerrogativa funcional posta como encargo em decorrência do elo filial e cujo conjunto de deveres é assumido em favor do filho, criança ou adolescente em peculiar situação de desenvolvimento da personalidade, preservando-lhe e promovendo seus interesses (ALMEIDA; RODRIGUES JR., 2012, p.447-448). Esses deveres estão expressos no art. 1.634 do Código Civil de 2002.

Neste trabalho, interessa abordar o conteúdo da autoridade parental em relação à pessoa dos filhos, mais especificamente no que tange ao direito fundamental destes à convivência familiar - cujo dever-ser é a primazia do bem-estar dos infantes, em consonância com o princípio do melhor interesse.

Esse princípio bem como o dever de proteção especial à infância, que deram ensejo à chamada Doutrina da Proteção Integral, foram reconhecidos amplamente na seara internacional em 1989 na Convenção Internacional sobre os Direitos da Criança (Resolução 44/25 da Assembleia Geral da ONU). 


\section{Revista da Faculdade Mineira de Direito $\mid$ v.20 N.40|248}

No Brasil, a Constituição de 1988 seguiu as tendências internacionais, rompendo com a Doutrina Menorista no seu art. $227^{3}$, posteriormente reproduzido em 1990 no art. $3^{\circ}$ do Estatuto da Criança e do Adolescente (ECA). Nele, há uma série de direitos fundamentais das crianças e dos adolescentes, de modo a corresponsabilizar a família, a sociedade e o Estado pela sua garantia com absoluta prioridade.

Sendo o núcleo familiar a base da sociedade ${ }^{4}$ e ambiente natural de desenvolvimento do indivíduo, cabe a ele, em primeiro lugar, garantir tais direitos fundamentais, dentre eles o de convivência familiar. Por isso, atribui-se aos genitores o encargo da autoridade parental. Há, entretanto, grande dificuldade em assegurar a continuidade da convivência saudável com ambos os pais quando ocorre a cisão do núcleo familiar. A obstrução do contato familiar trata-se de ato ilícito que se caracteriza com o descumprimento de um dever.

Para além dos conflitos jurídicos que permeiam o contexto de separação dos pais, pretende-se analisar esse cenário sob a perspectiva da psicologia, uma vez que o conflito da alienação parental pode ser nesse aspecto tormentoso.

Em uma pesquisa, Hameister, Barbosa e Wagner (2015) analisaram 76 (setenta e seis) artigos científicos produzidos no mundo inteiro nos 10 (dez) anos que antecederam a pesquisa que mapeou o conflito conjugal e suas reverberações na parentalidade e no desenvolvimento dos filhos. As autoras mencionam Erel e Burman (1995), responsáveis por elaborar uma das hipóteses explicativas da dinâmica da influência recíproca entre conjugalidade e parentalidade: o efeito spillover.

O spillover trata-se da existência de um "transbordamento do clima emocional da relação de conjugalidade dos progenitores para a

3“'É dever da família, da sociedade e do Estado assegurar à criança, ao adolescente e ao jovem, com absoluta prioridade, o direito à vida, à saúde, à alimentação, à educação, ao lazer, à profissionalização, à cultura, à dignidade, ao respeito, à liberdade e à convivência familiar e comunitária, além de colocá-los a salvo de toda forma de negligência, discriminação, exploração, violência, crueldade e opressão." (BRASIL, 1988, com redação dada pela EC n ${ }^{\circ}$ 65/2010)

4 “Art. 226. A família, base da sociedade, tem especial proteção do Estado." (BRASIL, 1988) 
parentalidade e vice-versa." (HAMEISTER; BARBOSA; WAGNER, 2015, p.141). Aduzem as autoras (2015, p.141-142) que uma das variáveis desse efeito é o conflito conjugal, que pode ser tratado pelos genitores de modo construtivo ou destrutivo, propiciando diferentes impactos no contexto familiar.

Nesta pesquisa, interessa abordar agora o efeito spillover do conflito conjugal destrutivo nas consequências negativas que podem dele advir. Tal reverberação pode ser direta, pela exposição ao conflito conjugal, ou indireta, decorrente de alterações de conduta de um ou de ambos os cônjuges ou dos sentimentos gerados na criança ou adolescente (HAMEISTER; BARBOSA; WAGNER, 2015, p.145-144).

Cabe mencionar os resultados das pesquisas analisadas que demonstram como esse ambiente de conflitos conjugais destrutivos pode impactar tão negativamente na parentalidade, especialmente quando da separação do casal, pois esses conflitos estão potencializados e potencializadas também serão as suas consequências em relação aos filhos.

Variáveis como a hostilidade entre os cônjuges (Benson, Buehler, \&Jerard, 2008; Feldman et al., 2010; Low\&Stocker, 2005), o aumento da exposição ao conflito ao longo do tempo (Atkinson, Dadds, Chipuer, \&Dawe, 2009; Schermerhorn, Cummings, De Carlo, \& Davies, 2007) e o estresse familiar (Flook\&Fuligni, 2008), assim como as práticas parentais de controle psicológico e de menor compreensão e empatia (Benson et al.,2008), se mostraram bastante potentes na relação entre os problemas de ajustamento dos filhos (expressão de comportamentos inter e externalizantes) e os conflitos conjugais.

Tais distúrbios também podem estar relacionados, mediados ou moderados por características dos próprios filhos advindas da situação conflituosa, tais como sentimentos de culpa, estresse (Ablow, Measelle, P. A. Cowan, \& C. P. Cowan, 2009) e insegurança emocional (Kouros, Merrilees, \&Cummings, 2008).

$[\ldots]$

A parentalidade ainda se mostrou comprometida quando maiores níveis de conflito conjugal levaram à confusão de papéis, fazendo com que os filhos se sentissem 
impelidos a cuidar de seus pais, e estes, a envolvê-los em sua conjugalidade (Peris, Goeke-Morey, Cummings, \& Emery, 2008). (HAMEISTER; BARBOSA; WAGNER, 2015, p. 146) (grifou-se)

Em investigação empírica, qualitativa, por meio de entrevistas individuais com 30 (trinta) pessoas da classe média, residentes no Rio de Janeiro, na faixa etária de 21 (vinte e um) a 29 (vinte e nove) anos, filhos de pais separados, Brito (2007, p.34) ao citar Giddens (1999, p.102) pauta que "os efeitos do divórcio na vida dos filhos serão sempre de difícil avaliação, porque não sabemos o que teria acontecido se os pais estivessem juntos".

$\mathrm{Na}$ análise de conteúdo dos dados colhidos, Brito (2007, p.37) aponta que, em relação à separação, alguns entrevistados indicaram que, apesar de não gostarem dos conflitos entre seus pais, a que estavam diretamente expostos, "não sentiram tanto a separação, mas foram afetados pelos desdobramentos desta.".

Alguns interlocutores admitiram que, após o rompimento conjugal, não sofreram alterações na rotina, pois continuaram a residir na mesma casa. No entanto, destacaram como a maior consequência o distanciamento acentuado do genitor com quem não residia, "afastamento do qual se ressentiam constantemente, devido ao aspecto emocional e, por vezes, físico.” (BRITO, 2007, p. 39).

Ainda no que tange ao convívio com pais, Brito (2007, p. 41) destaca a possibilidade de os filhos estabelecerem alianças com o genitor com quem residem e que, na guarda unilateral, seria a figura do guardião. Desenvolvem uma forte vinculação com esse genitor, a quem percebem de maneira positiva. Afirma que na pesquisa tal polarização do afeto foi encontrada mais frequentemente entre mães e filhos caçulas, os quais eram bem pequenos no momento da separação e a quem a genitora direcionava toda a sua afetividade. E acrescenta: "ao longo do desenvolvimento, muito apegada à mãe, a própria criança não conseguia se afastar para visitar o pai, iniciando-se uma série de justificativas que, prontamente, eram defendidas pela mãe." (BRITO, 2007, p.41). 
Por fim, Brito (2007, p.41) também observou o fenômeno dos filhos cuidadores. Alguns entrevistados, com o advento da separação dos genitores, passaram a se preocupar mais com o genitor com quem residia, tornando-se quase responsável por este, em uma notável inversão de papéis.

Cumpre pontuar aqui, como bem lembra Sousa e Amendola (2012, p.92), que os comportamentos dos genitores e seus filhos nessas situações não resultam diretamente da separação conjugal ou de disposições singulares, tornando-se imperioso percebê-los "na interseção de aspectos singulares e sociais, sendo que os filhos podem dar tanto sustentação quanto contribuir para fragilizar as relações parentais.”.

Fato é que conflitos destrutivos entre os genitores casados podem não cessar com a separação conjugal. Mesmo após a dissolução do vínculo familiar entre os pais, tais conflitos produziram seu efeito spillover sobre a relação parental.

Compreende-se que a separação, imbuída de emoções, pode ser duplamente desafiadora para o ex-casal: a reconstrução da identidade de cada um que pode ter se mesclado com a conjugalidade e a manutenção da relação parental, resguardando as individualidades de cada genitor (BRITO, 2005).

Soares (2009, p. 59) aponta para "a dificuldade dos pais em se perceberem como responsáveis pelo exercício da parentalidade, quando a atenção está voltada para a sua conjugalidade". Ainda, segundo Brito (2002),

os sentimentos negativos direcionados ao ex-cônjuge devido à separação podem contribuir para o afastamento dos filhos, pois alguns pais se deparam com a contradição entre querer distanciar-se do ex-cônjuge e não podê-lo por conta da parentalidade que os une.

Nesse turbilhão conflituoso não raro é a confusão entre conjugalidade e parentalidade, as quais, acaso potencializadas, podem dar ensejo à alienação parental. 


\section{SAP E ALIENAÇÃO PARENTAL: DISTINÇÃO E CONCEITUAÇÃO}

Apesar de o fenômeno da alienação parental já permear há muito tempo os conflitos familiares (MIRANDA JR., 2014), no Brasil a maior discussão em torno do tema se deu após a promulgação da Lei $\mathrm{n}^{\circ} 12.318$ de 26 de agosto de 2010, também conhecida como Lei da Alienação Parental, que conceituou o fenômeno conflituoso, destacando-o na mídia, inclusive.

A popularização da alienação parental, a despeito de gerar maior alerta e conscientização sobre o exercício da parentalidade, abriu margem para que, ante a qualquer dificuldade de exercício da autoridade parental, especialmente no que tange à convivência familiar, um dos genitores passe a alegar que o outro está alienando o filho comum.

Atenta-se aos cuidados que devem ser adotados nos casos que houver imputação da alienação parental a um dos genitores ou a qualquer pessoa que tenha a criança ou adolescente sob sua autoridade, guarda ou vigilância. A fim de compreender melhor esse fenômeno conflituoso, farse-á a conceituação da alienação parental e a sua distinção em relação à Síndrome da Alienação Parental - SAP.

A Síndrome da Alienação Parental - SAP foi cunhada em 1985 pelo pedopsiquiatra estadunidense, professor na Universidade de Columbia, Richard Gardner (1931-2003), que concluiu tratar-se de um distúrbio que ocorre especialmente em crianças e adolescentes ante as situações de disputas judiciais entre os genitores.

Em linhas gerais, a alienação parental consiste na "programação" feita por um parente, geralmente um genitor, para desvalorizar o outro genitor. Além disso, Gardner (2002) observou que há também contribuições criadas pela própria criança ou adolescente em apoio à campanha depreciativa do genitor alienador contra o genitor alienado.

Não obstante o reconhecimento de que nesse contexto de separação litigiosa há dificuldades relacionais envolvendo todos do grupo familiar, Gardner opta por fazer uma abordagem individual e patológica 


\section{Revista da Faculdade Mineira de Direito $\mid$ V.20 N.40 253}

do fenômeno, estabelecendo que o diagnóstico da SAP devesse ser aferido dos sintomas exibidos pelos infantes.

Similarmente, a SAP é caracterizada por um conjunto de sintomas que aparecem na criança, geralmente juntos, especialmente nos tipos moderado e severo. Esses incluem:

1. Uma campanha denegritória contra o genitor alienado.

2. Racionalizações fracas, absurdas ou frívolas para a depreciação.

3. Falta de ambivalência.

4. O Fenômeno do "pensador independente" [falsas memórias].

5. Apoio automático ao genitor alienador no conflito parental.

6. Ausência de culpa sobre a crueldade a e/ou exploração contra o genitor alienado.

7. A presença de encenações "encomendadas".

8. Propagação de animosidade aos amigos e/ou à família extensa do genitor alienado. (GARDNER, 2002, p.3)

Gardner pontua que o alienador, ou programador, age por raiva, desejo de vingança ou ciúmes em relação ao ex. Ainda, "que a alienação poderia ser um modo de vida profundamente integrado a estrutura psíquica do alienador, de tal maneira que, em alguns casos, a ruptura do casamento, aliada a disputas judiciais, poderia precipitar transtornos psiquiátricos" (SOUSA; AMENDOLA, 2012, p.100).

Contudo, a teoria de Gardner foi veementemente criticada, por ser sexista, ao assegurar, inicialmente, que na maioria dos casos a mãe guardiã era a responsável pela alienação dos filhos; e pela falta de rigor científico, ante a ausência subsídio empírico em sua pesquisa. Amparava comumente suas conclusões em argumentações lógicas e analogias com doenças físicas (MOREIRA, 2013, p. 44; SOUSA, AMENDOLA, 2012, p.104).

Por isso, a inclusão da SAP foi recusada na Classificação Internacional de Doenças e Problemas Relacionados à Saúde - CID-10, da 
Organização Mundial da Saúde - OMS, e nunca foi incorporada no DSM ${ }^{5}$ da Associação de Psicólogos Americanos - APA (MOREIRA, 2013, p.44).

Reconhece-se aqui que a teoria da SAP teve a sua importância ao suscitar um abuso emocional silencioso, mas com um potencial gigantesco de destruir laços parentais e gerar consequências psicológicas negativas para todos os envolvidos. No entanto, resta claro que sua visão patológica e individual do fenômeno é reducionista; serve para criar uma dicotomia entre os envolvidos (MIRANDA JR., 2014) e remonta a uma antiga associação da psiquiatria com a justiça: ratificar a punição como controle social (MOREIRA, 2013, p. 46).

Enquanto a SAP está focada nos sintomas aferidos individualmente da criança e do adolescente num contexto de disputa judicial entre os genitores em sede de rompimento do vínculo conjugal ou de companheirismo, a alienação parental - sem a denominação de síndrome -, como proposta por Douglas Darnall (1997), refere-se aos atos do genitor alienador em afastar ou impedir o exercício da autoridade parental, impactando a convivência familiar - o que pode dar ensejo aos sintomas notáveis nos infantes.

Essa foi a perspectiva sobre o fenômeno adotada na Lei $n^{\circ}$ 12.318/2010, cujo art. $2^{\circ}$ dispõe:

Considera-se ato de alienação parental a interferência na formação psicológica da criança ou do adolescente promovida ou induzida por um dos genitores, pelos avós ou pelos que tenham a criança ou adolescente sob a sua autoridade, guarda ou vigilância para que repudie genitor ou que cause prejuízo ao estabelecimento ou à manutenção de vínculos com este.

Para melhor auxiliar os cidadãos e especialmente os agentes da justiça a identificarem a possível presença desse fenômeno conflituoso o

${ }^{5}$ Manual de Diagnósticos e Estatísticas de Doenças Mentais - Diagnostic and Statistical Manual of Mental Disorders -, em sua quinta edição (DSM-5), é um padrão de classificação de doenças mentais usado por profissionais de saúde mental nos Estados Unidos (APA, online. Disponível em: https://www.psychiatry.org/psychiatrists/practice/dsm. Acesso em: 31 mai. 2016). 


\section{Revista da Faculdade Mineira de Direito $\mid$ v.20 N.40|255}

legislador destacou, no parágrafo único do art. $2^{\circ}$ da Lei no 12.318/2010, um rol exemplificativo de condutas alienantes:

São formas exemplificativas de alienação parental, além dos atos assim declarados pelo juiz ou constatados por perícia, praticados diretamente ou com auxílio de terceiros:

I - realizar campanha de desqualificação da conduta do genitor no exercício da paternidade ou maternidade;

II - dificultar o exercício da autoridade parental;

III - dificultar contato de criança ou adolescente com genitor;

IV - dificultar o exercício do direito regulamentado de convivência familiar;

$\mathrm{V}$ - omitir deliberadamente a genitor informações pessoais relevantes sobre a criança ou adolescente, inclusive escolares, médicas e alterações de endereço;

VI - apresentar falsa denúncia contra genitor, contra familiares deste ou contra avós, para obstar ou dificultar a convivência deles com a criança ou adolescente;

VII - mudar o domicílio para local distante, sem justificativa, visando a dificultar a convivência da criança ou adolescente com o outro genitor, com familiares deste ou com avós.

Ante a criatividade do alienador, imprudente seria tentar abarcar todas as condutas possíveis numa lista. Moreira (2013, p. 50) alerta sobre as tentativas de anular a participação do outro genitor em decisões importantes na vida dos filhos, tais como acerca do rendimento escolar, mudança de escola, acompanhamento médico, dentário ou psicológico.

Observa-se que muitos dos indícios de alienação parental levantados pela literatura do tema são alguns sintomas potencializados do efeito spillover de conflitos destrutivos entre os genitores. A lealdade criada entre o genitor programador e o filho diz sobre o apego e as alianças com o genitor com quem a criança ou o adolescente reside. A sensação de dever de cuidado que o infante tem em relação ao seu alienador, em virtude deste lhe confessar sentimentos negativos em relação às experiências passadas com outro genitor, diz sobre a inversão de papéis. A campanha de desqualificação da conduta do genitor diz sobre 
desqualificações de características do infante, remetendo-as a atributos do ex.

Cumpre pontuar que nem sempre a alienação parental é feita de modo consciente pelo alienador. Sintomas aferíveis do fenômeno conflituoso da alienação parental, os quais provavelmente lhe dão causa, dizem muito mais do inconsciente (MIRANDA JR., 2014).

\section{A RESPONSABILIZAÇÃO DO ENTE ALIENADOR EXPRESSA NO ORDENAMENTO JURÍDICO BRASILEIRO}

Caracterizado o conflito da alienação parental, volta-se a atenção para as consequências desse fenômeno, notadamente os danos decorrentes do abuso psicológico sofrido pelo infante, da deterioração da parentalidade e do esvaziamento da relação afetuosa com o outro genitor.

Como a alienação parental potencializa o spillover, não é de se admirar que a criança arque com "drásticas consequências imediatas e futuras para seu desenvolvimento psíquico e emocional"(MOREIRA, 2013, p.52).

No documentário "A morte inventada" (2009), foram expostos 7 (sete) casos de alienação parental. Oportunizou o espaço de fala para vítimas de alienação quando crianças e, ainda, na adolescência, mas que posteriormente perceberam que sofriam desse tipo de abuso e para parentes alienados - mãe, pais e avô.

Desses depoimentos extraem-se dois fatos peculiares. O primeiro é que a alienação parental gera no infante um sentimento de abandono por parte do genitor dito alienado e mesmo quando já jovem a pessoa percebe que está sendo ou foi alienada. Além disso, não surge um sentimento de complacência em relação a este genitor, por julgar que este não lutou suficientemente para cumprir seu dever de resguardar a convivência familiar.

Daí decorre o segundo fato: na maioria dos casos infere-se responsabilização dos genitores pela ocorrência do fenômeno da alienação parental, seja por atitude comissiva - o alienador - ou omissiva - o alienado. 
Ao se atentar de modo mais cauteloso a complexidade do fenômeno da alienação parental, percebe-se que há uma corresponsabilidade de ambos os pais, o que foge da lógica simplista e dual que "tenderia a dizer de um doente e do outro vítima e isso não é o correto na maioria das experiências.” (MIRANDA JR, 2014). O mesmo autor ainda assevera que tal lógica

responde muito bem a um discurso jurídico que precisa dos pólos [...] opostos, onde um está correto e o outro incorreto no que está fazendo. E a gente sabe que [...] nas relações familiares isso não é tão simples assim. [...] $\mathrm{Na}$ alienação parental muitas vezes a gente encontra a participação dos dois, [...] na forma ativa ou passiva. (MIRANDA JR., 2014)

Não obstante o fenômeno da alienação parental em si não ter sido criminalizado quando do advento da Lei $\mathrm{n}^{\mathrm{o}}$ 12.318/2010, a normativa expressamente prevista nela com vistas a coibir esse conflito e inibir seus efeitos mostrou-se ineficiente na garantia do livre desenvolvimento da personalidade da criança e do adolescente.

$\mathrm{O}$ artigo $6^{\circ}$ da Lei $n^{\circ} 12.318 / 2010$ elenca rol de hipóteses de resposta do Poder Judiciário às partes litigantes caso esteja configurada a alienação parental, atestada por perícia psicológica ou biopsicossocial nos termos do art. $5^{\circ}$ da referida lei.

Art. 6o Caracterizados atos típicos de alienação parental ou qualquer conduta que dificulte a convivência de criança ou adolescente com genitor, em ação autônoma ou incidental, o juiz poderá, cumulativamente ou não, sem prejuízo da decorrente responsabilidade civil ou criminal e da ampla utilização de instrumentos processuais aptos a inibir ou atenuar seus efeitos, segundo a gravidade do caso:

I - declarar a ocorrência de alienação parental e advertir o alienador;

II - ampliar o regime de convivência familiar em favor do genitor alienado;

III - estipular multa ao alienador;

IV - determinar acompanhamento psicológico e/ou biopsicossocial; 
V - determinar a alteração da guarda para guarda compartilhada ou sua inversão;

VI - determinar a fixação cautelar do domicílio da criança ou adolescente;

VII - declarar a suspensão da autoridade parental.

Parágrafo único. Caracterizado mudança abusiva de endereço, inviabilização ou obstrução à convivência familiar, o juiz também poderá inverter a obrigação de levar para ou retirar a criança ou adolescente da residência do genitor, por ocasião das alternâncias dos períodos de convivência familiar. (grifou-se)

É evidente que tais respostas possuem caráter sancionador frente ao ente alienador. Tanto que o juiz pode aplicar uma das hipóteses acima de modo cumulativo ou não, mas sempre conforme a gravidade de cada caso. Isso se aproxima mais ao princípio da proporcionalidade do Direito Penal, cuja pena cominada deve ser de acordo com a gravidade do ilícito (GRECO, 2003, p.82), do que da responsabilização civil, estabelecida de acordo com a extensão do dano efetivo.

Apesar de o rol de respostas ser exemplificativo, diante do escopo deste artigo, somente se analisarão as hipóteses elencadas pelo legislador.

O inciso I prevê a declaração de ocorrência de alienação parental e a advertência ao alienador, com nítida lógica dual, estigmatizando o genitor como alienador e lhe atribuindo de forma exclusiva toda a responsabilidade pela alienação - vimos que essa não é a realidade na grande maioria dos casos. Tanto é que a advertência prevista é dirigida somente ao alienador e não a todos os adultos juridicamente interessados e diretamente envolvidos. Ademais, cumpre ressaltar que tal advertência sugere revestir-se mais como uma atemorização em possível busca e apreensão do infante.

Os incisos II, a primeira parte do V e o VI, todos do art. $6^{\circ}$ da Lei $\mathrm{n}^{\circ}$ 12.318/2010, que dispõem respectivamente sobre a ampliação da convivência familiar em favor do alienado, a determinação da guarda compartilhada e a fixação do domicílio da criança ou do adolescente, de fato preconizam garantias à convivência familiar saudável, direito 
fundamental do infante, nos termos da Doutrina da Proteção Integral. No entanto, a forma como são impostas simboliza uma sanção.

Dá a entender, principalmente para as partes, que a determinação da guarda compartilhada, por exemplo, somente ocorreu e só deveria haver em virtude da constatação da alienação parental para infligir um prejuízo ao alienador. O viés não parece ser de oportunizar um melhor ambiente para o desenvolvimento da personalidade da criança ou do adolescente, inclusive para reparar-lhes os danos da alienação.

Quanto à estipulação de multa prevista no inc. III, trata-se de uma previsão esdrúxula, pois ratifica o caráter punitivo das medidas do art. $6^{\circ}$ da Lei n ${ }^{\circ}$ 12.318/2010 e, portanto, não é preventiva, mas cominatória, repressiva e, tal como no Direito Penal, demonstra seu caráter retributivo e dissuasivo, supostamente "pedagógico".

Moreira (2013, p.66) ainda aponta que "não se pode olvidar que o pagamento de tal numerário poderá remeter o alienador a uma justificada dificuldade financeira, a ponto de comprometer principalmente sua própria subsistência e sustento do filho".

Destaca-se também a aparente lacuna da destinação da multa aplicada. Moreira (2013, p. 66) bem demonstra que, apesar de não estar previsto expressamente no art. $6^{\circ}$, III da Lei $\mathrm{n}^{\circ} 12.318 / 2010$, o valor arrecadado em sede de multa deve ser destinado ao fundo gerido pelo Conselho Municipal dos Direitos da Criança e do Adolescente, em consonância ao disposto no art. 214 do ECA. Moreira também justifica tal destinação "até mesmo para que a medida não induza o aumento da animosidade do genitor alienador, tendo em vista a perda financeira em favor de seu então 'adversário" - o que corrobora a perspectiva de que a multa só tende a potencializar o conflito, afetando sobremaneira o infante.

Em relação à inversão da guarda disposta ao final do inciso $\mathrm{V}$ do art. $6^{\circ}$ da Lei n ${ }^{\circ} 12.318 / 2010$, sua imposição só faz sentido quando não for aplicável a guarda compartilhada, que é a regra segundo $₫ 2^{\circ}$ do art. 1584 do CC/2002, e ainda de forma não abrupta, tendo em vista os riscos de lesar mais uma vez o infante, uma vez que este, alienado, torna-se deveras apegado e leal ao alienador, venerando-o e amando-o 
profundamente. Além disso, a inversão certamente vem revestida como sanção ao alienador.

Ademais, no que tange ao atendimento psicológico e/ou biopsicossocial previsto no inciso IV do art. $6^{\circ}$ da Lei da Alienação Parental, atenta-se para a sua importância no tratamento dos sintomas do fenômeno. Não obstante, tal se dará de modo compulsório, deixando transparecer novamente seu caráter sancionador, o que pode comprometer em excesso a sua efetividade.

Por fim, tem-se como medida mais austera a ser aplicada a suspensão da autoridade parental - art. 6º VII da Lei no 12.318/2010 -, enquadrando-se na hipótese de descumprimento de dever parental, nos termos do art.1.637 do CC/2002.

Percebe-se que as respostas previstas pelo legislador em relação à alienação parental, na Lei no $12.318 / 2010$, são ineficientes em promover a transformação desse fenômeno conflituoso destrutivo complexo. Ainda que o rol do art. $6^{\circ}$ da referida lei seja exemplificativo, há uma forte tendência do Poder Judiciário de se posicionar nesses casos de modo adstrito ao que foi arrolado pelo legislador. Desse modo, não se estará promovendo a responsabilização ativa do ente alienador, a corresponsabilização dos envolvidos e muito menos a reparação dos danos, principalmente daqueles sofridos pela criança ou adolescente.

\section{A PRÁTICA RESTAURATIVA COMO POSSIBILIDADE}

Diante da complexidade desse fenômeno conflituoso, tem-se que uma decisão judicial dificilmente será apta a (re)estabelecer um ambiente de convivência familiar saudável. Do contrário: ante à formalidade regente do provimento jurisdicional, muitas vezes uma decisão heterônoma, não suficientemente atenta à lide sociológica e psicológica envolvida no caso, potencializará o conflito preexistente. Torna-se imperioso, portanto, retomar a compreensão de acesso à justiça.

Considera-se, aqui, o acesso à justiça enquanto um acesso material, um dos pilares do Estado Democrático de Direito, por ser um princípio garantidor dos direitos humanos. Cappelletti e Garth $(1988$, p.2) lecionam 
que esse acesso a uma ordem jurídica justa é o mais elementar dos direitos humanos, pois efetiva direitos e não meramente proclama-os.

Nesse sentido, Boaventura de Sousa Santos (2011, p.41) aponta para a utilização de métodos autônomos de resolução dos conflitos sob a perspectiva da justiça comunitária, uma vez que essa experiência presta orientação jurídica e dá "solução a problemas que não poderiam ser solucionados devidamente no judiciário por não se adequarem às exigências formais/probatórias do juízo ou porque não obteriam uma pronta resposta da justiça oficial."

Mais especificamente, Miranda Jr. (2015, p.226-227) bem explica acerca da judicialização dos conflitos familiares que

o fato ou fenômeno familiar, ao entrar no discurso jurídico, é 'ajustado' a esse discurso para legitimar a possibilidade de demanda. [...] O efeito deste 'ajuste' é [...] a perda da palavra do sujeito. Quem fala pelos interessados no discurso jurídico são aqueles autorizados a fazê-lo, os operadores do direito.

Como se sabe, o novo CPC, dentro dos limites do discurso legislativo, tenta promover uma nova racionalidade para o trato das litigiosidades.

Ao se analisar o disposto no art. $3^{\circ}$ do Novo $\mathrm{CPC}^{6}$, percebe-se notória tendência de se estruturar um modelo multiportas que adote a solução jurisdicional tradicional agregada à absorção de outros meios. Busca-se, assim, a adoção de uma solução integrada dos litígios, como corolário da garantia constitucional do livre acesso à jurisdição constante do inc. XXXV do art. $5^{\circ}$ da CRFB/88.

\footnotetext{
${ }^{6}$ Art. $3^{\circ}$ Não se excluirá da apreciação jurisdicional ameaça ou lesão a direito. $\S 1^{\circ}$ É permitida a arbitragem, na forma da lei. $\S 2^{\circ} \mathrm{O}$ Estado promoverá, sempre que possível, a solução consensual dos conflitos. $\S 3^{\circ}$ A conciliação, a mediação e outros métodos de solução consensual de conflitos deverão ser estimulados por magistrados, advogados, defensores públicos e membros do Ministério Público, inclusive no curso do processo judicial.
} 
Nos termos postos, vislumbra-se que, para além de se pensar na jurisdição como última via para se dimensionar um conflito, hoje é possível se pensar que as chamadas técnicas alternativas, podem ser utilizadas como vias plúrimas e adequadas para a solução mais apropriada, quando bem estruturadas e levadas a cabo de modo profissional, independentemente do nível de complexidade do conflito que se apresente.

No que tange às demandas familiares, a abertura de meios que congreguem a atuação técnica jurídica com outros saberes (v.g. psicologia, serviço social) se torna imperativa para atuar nos níveis de complexidade ínsitos das relações interpessoais afetivas da atual quadra histórica.

A ideia parte da noção de que os litígios, especialmente dentro de um quadro de diversidade de tipos e de graus de complexidade, merecem ser geridos e direcionados para a via processual adequada para seu dimensionamento.

Nestes termos, no novo CPC, verifica-se que a mediação e a conciliação, de técnicas alternativas, passam a compor um quadro de soluções integradas de modo que, uma vez proposta a demanda, haveria a possibilidade de escolha da técnica mais adequada para o dimensionamento de cada conflito.

Assim, apesar das duras críticas que se podem fazer à tendência de absorção destas técnicas no bojo do processo jurisdicional, o novo CPC, buscando reduzir os déficits de sua eficiência, em face, inclusive, da ausência de profissionalismo no uso das técnicas, tenta promover um peculiar modelo multiportas no qual o processo judicial encampa a solução adjudicada (jurisdicional), além da possibilidade endoprocessual de uma conciliação e/ou mediação profissionalizada.

Isto permitirá, caso bem implementado, a mudança do atual perfil do dimensionamento dos conflitos em geral e, em especial, dos familiares.

Contudo, tendo em vista a perspectiva do sistema multiportas, aqui entendido na sua forma mais ampla, não restrita somente às diversas portas institucionalizadas pelos Tribunais, mas também às portas extrajudiciais, e da cultura de paz, pretende-se apontar a prática restaurativa de processos circulares como um método possível a ser 


\section{Revista da Faculdade Mineira de Direito $\mid$ V.20 N.40 263}

aplicado no fenômeno conflituoso e complexo da alienação parental, a fim de se garantir o acesso à ordem jurídica justa, conforme os ditames da Doutrina da Proteção Integral.

A prática restaurativa de processos circulares é um dos instrumentos utilizados para se efetivar a chamada Justiça Restaurativa ${ }^{7}$. Sua aplicabilidade é ampla, podendo ser utilizada em diversas situações, adequando-se à singularidade de cada caso. Os processos circulares dão-se através de círculos de paz, denominados também de restaurativos, cujas finalidades são variadas.

Nele reúnem-se voluntariamente as partes, seus familiares, amigos, outros membros da comunidade - que pertencem à denominada rede primária de interessados -, bem como a sociedade representada por operadores do direito - "juiz, promotor, advogado de defesa, polícia, oficial de condicional e outros profissionais." (PRANIS, 2010, p.30). Os participantes dialogam acerca do evento danoso, a razão de ele ter ocorrido, qual dano ele ocasionou e o que é necessário para repará-lo e evitar a repetição, buscando-se o consenso.

Cumpre destacar a peculiaridade do círculo restaurativo. Trata-se de uma metodologia antiga, inspirada em antigas tradições tribais e que "hoje se mescla aos conceitos contemporâneos de democracia e inclusão, próprios de uma sociedade complexa e multicultural" (PRANIS, 2010, p. 15). É um método dialógico em que pessoas interessadas e envolvidas voluntariamente participam.

Usando elementos estruturais intencionais (cerimônias, um bastão de fala, um facilitador ou coordenador, orientações e um processo decisório consensual) os Círculos objetivam criar um espaço onde os participantes se sentem totalmente autênticos e fiéis a si mesmos. (PRANIS, 2010, p. 25-26)

\footnotetext{
${ }^{7}$ Em linhas gerais, a Justiça Restaurativa é um modelo de justiça que se opõe ao paradigma vigente de Justiça Retributiva. Não se pretende a punição por uma ofensa a um bem-jurídico social, mas sim - a partir do reconhecimento autônomo dos fatos - a responsabilização ativa do ofensor na reparação dos danos causados à vítima, a restauração do tecido social rompido pelo crime, a reintegração de vítimas e ofensores na sociedade, observando às possibilidades e necessidades de ambas as partes.
} 


\section{Revista da Faculdade Mineira de Direito $\mid$ v.20 N.40|264}

No círculo, os participantes sentam-se em roda, sem mesa ao centro, simbolizando horizontalidade, igualdade, conexão, inclusão, ausência de barreiras.

Nele as partes são incentivadas a criarem princípios orientadores dos círculos, quando se solicita aos participantes que eles digam o que querem para si mesmos dos outros e, posteriormente, de modo consensual, tais princípios orientadores aplicam-se a todos no círculo. As orientações tratam-se antes de um esclarecimento das expectativas de condutas construídas conjuntamente para que os participantes se sintam seguros o suficiente para serem sinceros e autênticos, figurando como lembretes de um compromisso firmado, do que de regras e limites rígidos. Pranis (2010, p.50) explica que dentre os princípios orientadores sempre se encontram a fala e a escuta respeitosa, bem como a confidencialidade.

Credita-se muito a promoção eficaz da escuta ativa no ambiente do círculo à utilização do bastão de fala. Esse elemento estrutural é um objeto que possui uma simbologia para os envolvidos e que passa de pessoa para pessoa dando a volta na roda e possibilitando a todos a oportunidade de fala e de escuta, uma vez que somente o detentor do bastão tem a palavra, enquanto os outros "têm a oportunidade de escutar sem pensar numa resposta" (PRANIS, 2010, p.51).

O círculo também possui uma aparente semelhança com outros métodos autônomos de resolução de conflito ao eleger como elemento estrutural um facilitador. Este, também chamado de cuidador ou guardião, não é responsável por sugerir soluções ou controlar o grupo. "Seu papel é o de iniciar um espaço respeitoso e seguro e envolver os participantes na partilha da responsabilidade pelo espaço e pelo trabalho em comum." (PRANIS, 2010, p. 53).

Diferentemente do que ocorre na mediação, por exemplo, o facilitador participa do processo e pode oferecer seus pensamentos, ideias e histórias, mas sem sugerir acordos para a resolução do conflito. Minimizar seu viés de atuação é desejável no círculo, porém isso se consegue mediante cuidado e atenção acolhedores em relação a todos os participantes, em vez de um distanciamento clínico. $O$ facilitador preservase multiparcial ao se aproximar de forma equânime de todos. 
Nas primeiras rodadas do círculo há a partilha de valores, elaboração dos princípios orientadores, e a contação de histórias, "o facilitador é o modelo de vulnerabilidade na partilha de sentimentos profundos. As rodas devem ser dirigidas no sentido de uma partilha positiva." (PRANIS, 2010, p.59). Utiliza-se a contação de histórias antes de se adentrar no conflito em si (PRANIS, 2010, p.56-57), pois quebra a animosidade entre os envolvidos, os humaniza e nutre a empatia, criando rapport. Desse modo, estar-se-ão desconstruindo preconceitos com relação às outras pessoas envolvidas.

Optou-se por uma explicação da prática restaurativa de processos circulares a fim de demonstrar quão efetiva a aplicação dessa metodologia pode ser, sobretudo em fenômenos complexos como o da alienação parental. A própria autora KayPranis (2010, p. 32) admite a possibilidade de aplicação do método para "Dar apoio a famílias acusadas de negligência ou maus tratos a crianças e, ao mesmo tempo, garantir a segurança destas; [...] [e para] resolver conflitos familiares".

Tem-se no círculo um espaço informal, aconchegante, confidencial e horizontalizado apto a desconstruir a falácia do genitor alienador perverso e doente versus genitor alienado, cuja conduta é exemplar - tendo em vista a maioria dos casos de alienação que aportam no Judiciário.

Diferentemente do processo judicial e de outros métodos autônomos de resolução de conflito, o círculo não só considera o aspecto jurídico do conflito, como também os aspectos mentais, físicos, emocionais e espirituais, que compõem a experiência humana (PRANIS, 2010, p. 45) e, ainda, oportuniza a participação de uma rede de apoiadores daqueles diretamente envolvidos e que nunca deixaram de ser interessados nele, mesmo que de forma mediata - como familiares, membros da comunidade que as partes têm como referencial, assistentes sociais, professor do infante, psicólogos, entre outros.

Além disso, na maioria dos casos de alienação parental o genitor alienador causa um dano ao próprio filho de modo inconsciente. Por tal razão, acredita-se que a assunção de seus atos de alienação se dará de forma decorrente no ambiente de confiança do círculo. Não obstante, a contação de histórias e a vivência de outras perspectivas sobre o mesmo 


\section{Revista da Faculdade Mineira de Direito $\mid$ v.20 N.40|266}

fato favorecem a conscientização neste genitor acerca do efeito danoso da alienação.

Ademais, em princípio não se descarta a possibilidade de a criança ou o adolescente ser escutado em sessões individuais de pré-círculo ou mesmo no círculo, dependendo da análise do facilitador no caso concreto - possibilidade que por si só já é de grande valia tendo em vista condição de sujeito de direitos dos infantes.

Logo, mostra-se mais adequado propor às partes conflitantes métodos autônomos de resolução de conflito. Dentre eles, a prática restaurativa de processos circulares surge como uma possibilidade efetiva de abordagem do fenômeno conflituoso em sua plenitude.

Essa foi a intenção do legislador ao editar a Lei no 12.318/2010, notadamente em seu artigo $9^{\circ}$. O Projeto de Lei da Alienação Parental até quando submetido à sanção presidencial previa a utilização da mediação, judicial ou extrajudicial, como método de solução do litígio. Entretanto, tal artigo foi vetado pelo Presidente da República sob o fundamento do princípio da intervenção mínima e da indisponibilidade do direito de convivência familiar da criança e do adolescente.

Todavia, conforme já informado, o recém-promulgado Código de Processo Civil - Lei n ${ }^{\circ} 13.105 / 2015$ - incentiva, em seu art. $3^{\circ}$, dS $2^{\circ}$ e $3^{\circ}$, métodos consensuais de resolução de conflito. Mais especificamente no caso das ações de família, prevê, em seu art. 694, que todos os esforços serão empreendidos para a solução consensual da controvérsia.

Não se pode olvidar, ademais, que a também recente Lei de Mediação - Lei no 13.140/2015, que dispõe tanto sobre a mediação judicial como a extrajudicial, prevê em seu art. 42 que o disposto nessa lei será aplicado, no que couber, a outros métodos consensuais de resolução de conflito, tais como a prática restaurativa.

Sendo assim, aplica-se às práticas restaurativas o disposto no art. $3^{\circ}$ da Lei de Mediação, ou seja, direitos indisponíveis, mas transigíveis, podem ser objeto das práticas restaurativas e vindo as partes a chegar a um consenso, no caso de existência de interesses de incapazes, torna-se necessária a homologação do acordo em juízo, exigindo-se a oitiva do Ministério Público. 


\section{Revista da Faculdade Mineira de Direito $\mid$ v.20 N.40|267}

Esse parece ser o caso do direito fundamental à convivência familiar da criança e do adolescente - objeto central do diálogo nos casos de alienação parental -, pois se trata de um direito indisponível, mas que até mesmo para ser operacionalizado de modo saudável exige que os genitores o transacionem por meio do instituto da guarda.

Nesse sentido, percebe-se que a justificativa jurídica do veto presidencial do art. $9^{\circ}$ do Projeto de Lei que deu origem a Lei da Alienação Parental - Mensagem de Veto nº 513/2010 - é desarrazoada no que tange aos apontamentos acerca da convivência familiar, bem como acerca do princípio da intervenção mínima, previsto no art. 100, VII do Estatuto da Criança e do Adolescente, uma vez que este se dirige ao Estado, para que ele respeite a autonomia dos indivíduos que se diligenciam à proteção do infante.

A intervenção estatal só se torna cabível se indispensável para assegurar a promoção dos direitos da criança e do adolescente, segundo o referido inciso. Ora, resta evidente que quando os genitores envolvidos num conflito de alienação parental se voluntariam a participar de um método autônomo de resolução de conflitos, dialogando sobre a problemática posta para a promoção da convivência familiar saudável de seus filhos, a intervenção estatal torna-se absolutamente dispensável.

Insta ressaltar que aqui no nosso ordenamento jurídico não há uma previsão expressa acerca da aplicação das práticas restaurativas em conflitos familiares. Quando mencionadas, as práticas restaurativas estão atreladas à Justiça Restaurativa na esfera criminal ou em razão de conflitos no ambiente escolar, como no Plano Nacional de Direitos Humanos - 3, na Lei do Sinase, nas Resoluções no 118 do CNMP e no 125 e 225 do CNJ.

Especificamente em relação à Resolução no 225 do CNJ de 31 de maio de 2016, cumpre salientar que esta foi o primeiro instrumento normativo brasileiro de grande amplitude a conceituar a práticas restaurativas em seu art. $1^{\circ}$, III:

as praticas restaurativas terão como foco a satisfação das necessidades de todos os envolvidos, a responsabilização ativa daqueles que contribuíram direta ou indiretamente para a ocorrência do fato danoso e o empoderamento da 
comunidade, destacando a necessidade da reparação do dano e da recomposição do tecido social rompido pelo conflito e as suas implicações futuras.

Através das normativas acima explicitadas, nota-se que o Estado vem empreendendo esforços para que as práticas restaurativas sejam institucionalizadas dentro dos Tribunais, sob a perspectiva do acesso material à justiça e do sistema multiportas. No entanto, não se tem notícia da aplicação de práticas restaurativas em conflitos familiares, como os de alienação parental, dentro dos Tribunais.

Contudo, não há nenhum óbice à aplicação de práticas restaurativas nos casos de alienação parental de modo extrajudicial. Tal como a mediação, as práticas restaurativas podem ser utilizadas a qualquer tempo - extraprocessual, pré-processual, processual ou pós-processual. Quando não há processo em curso, chegando as partes a um consenso, o acordo pode ser homologado pelo juízo.

$\mathrm{Na}$ hipótese de haver processo em curso, como um processo de dissolução de união estável ou uma ação declaratória de alienação parental, por exemplo, as partes podem requerer conjuntamente a suspensão do processo durante período de sessões de círculo, nos termos do art. 16, caput, da Lei de Mediação c/c art. 694, parágrafo único do CPC/2015, e se diligenciarem a uma prática restaurativa extrajudicial. Estando o processo suspenso, os prazos processuais também o estão, conforme o art. 221, caput, CPC/2015.

Acredita-se que a aplicação das práticas restaurativas de modo judicial em conflitos familiares ainda não é possível somente em virtude de questões estruturais, como a escassez de facilitadores capacitados. Havendo o aparato dentro dos Tribunais, o caso poderá ser encaminhado para as práticas restaurativas e o processo ficará suspenso, inclusive com relação aos prazos, enquanto perdurar as sessões de círculos, nos termos dos artigos 694, parágrafo único; 696 e 221, parágrafo único, todos do CPC/2015 e do art. 16 da Lei no 13.140/2015.

Portanto, através de uma interpretação sistemática e teleológica do ordenamento jurídico brasileiro, sob a ótica da Doutrina da Proteção Integral da Criança e do Adolescente, que se esforça para a manutenção da 
convivência familiar, de modo saudável, em sua família originária, tem-se como legítimo o uso das práticas restaurativas de processos circulares como meio de responsabilizar ativamente o ente alienador, corresponsabilizar outros envolvidos, reparar os danos respeitando a necessidade de todos e restaurar os laços familiares e comunitários.

\section{CONCLUSÃO}

Havendo voluntariedade dos envolvidos, a prática restaurativa de processos circulares oportuniza a escuta ativa de todos os participantes, a exposição das necessidades de cada um, a responsabilização ativa pela alienação parental, a reparação dos danos e a restauração dos laços, principalmente com relação ao infante, promovendo assim o acesso a uma ordem jurídica justa, conforme preconiza a Doutrina da Proteção Integral, assegurando o direito fundamental da criança e do adolescente à convivência familiar saudável.

Portanto, a prática restaurativa de processos circulares abre a possibilidade para que o sujeito se autoconstitua por meio das oportunidades de transformação em seu ser singular, tornando-se sujeito de si mesmo, apropriando-se de sua experiência, estabelecendo, sobretudo por meio da escuta reflexiva, novos vínculos. As soluções são mais criativas e transformadoras, já que consideram a própria realidade vivenciada pelas partes e, reconhecendo-se e respeitando-se as diferenças, relacionamentos mais autênticos podem ser construídos.

Note que não se espera e tampouco é exigido que os genitores retomem o laço afetivo que outrora havia, mas sim se objetiva estreitar a relação de respeito e alteridade ética para que ela não seja desmantelada conjuntamente com o vínculo afetivo.

Cumpre ratificar que a lógica do presente trabalho foi emergir de modo inclusivo a prática restaurativa de processos circulares como uma das possibilidades que se têm no sistema multiportas na tratativa dos conflitos de alienação parental para a promoção do acesso material à Justiça. 
Frente a um caso concreto de alienação parental, cabe aos operadores do direito (juízes, promotores, advogados, conciliadores, mediadores, facilitadores, entre outros), por meio do mapeamento do conflito (SOLER, 2014), utilizando-se inclusive de Comunicação NãoViolenta (ROSENBERG, 2006), aferir qual é a metodologia de resolução mais adequada a ser aplicada, apresentando-a como uma possibilidade viável e efetiva para os envolvidos.

\section{REFERÊNCIAS}

A MORTE INVENTADA; alienação parental. Documentário. Direção e roteiro: Allan Minas. Produção: Daniela Vitorino. Fotografia: Fabio Regaleira. Edição: Marise Farias. Música: Clower Curtis. Duração: 80 minutos. Brasil, 2009. Idioma do Áudio: Português.

ALMEIDA, Renata Barbosa de; RODRIGUES JR., Walsir Edson. Direito Civil: Famílias. 2. ed. São Paulo: Atlas, 2012.

BRITO, Leila Maria Torraca de. Impasses na condição da guarda e da visitação: o Palco da Discórdia. 2002. In: CONGRESSO BRASILEIRO DE DIREITO DE FAMÍliA, 3, 2001, Ouro Preto. Anais... Belo Horizonte: Instituto Brasileiro de Direito de Família, 2002. Disponível em: $<\quad$ http://www.ibdfam.org.br/_img/congressos/anais/211.pdf $>$. Acesso em: 22 jun. 2016.

BRITO, Leila Maria Torraca de. Guarda compartilhada: um passaporte para a convivência familiar. In: Associação de Pais e Mães Separados (org.). Guarda Compartilhada: Aspectos Psicológicos e Jurídicos. Porto Alegre: Equilíbrio, 2005, p.53-71. 
Revista da Faculdade Mineira de Direito | v.20 N.40|271

BRITO, Leila Maria Torraca de. Família pós-divórcio: a visão dos filhos. Psicologia Ciência Profissão., Brasilia , v. 27, n. 1, p. 3245, Mar. 2007. Disponível em: <http:/ / www.scielo.br/scielo.php?script=sci_arttext\&pid=S141498932007000100004\&lng=en\&nrm=iso >. Acesso em: 26 maio 2016.

BRITO, Leila Maria Torraca de. (Org.). Escuta de Crianças e adolescentes: reflexões, sentidos e práticas. Rio de Janeiro: EdUERJ, 2012, v. 1, p. 87-118.

CAPPELLETTI, Mauro; GARTH, Bryant. Acesso à Justiça. Tradução Ellen Gracie. Northfleet. Porto Alegre: Fabris, 1988. Disponível em: <https://www.passeidireto.com/arquivo/2207246/acesso-a-justica--mauro-cappelletti-pdf>. Acesso em: 12 jun. 2016.

DARNALL, Douglas. Symptoms of Parental Alienation. 1997. Disponível em:<https://www.parentalalienation.com/articles/symptomsparental-alienation.html>. Acesso em: 07 jun. 2015.

EREL,Erel, O; BURMAN, B. Interrelatedness of marital relations and parent-child relations: a meta-analytic review. Psychological Bulletin. Whashington, v. 118, p. 108-132, Jul. 1995.

GARDNER, Richard Alan. Recent Trends in Divorce and Custody Litigation. The Academy Forum, [S.1.], v. 29, n. 2, p.3-7, 1985.Summer.Disponívelem:

<http://www.fact.on.ca/Info/pas/gardnr85.htm>. Acesso em: 07 jun. 2015.

GARDNER, Richard Alan. O DSM-IV tem equivalente para o diagnóstico de Síndrome de Alienação Parental (SAP)?.2002. Tradução por Rita Rafaeli. Disponível em: <http://www.alienacaoparental.com.br/textos-sobre-sap-1/o-dsm-ivtem-equivalente>. Acesso em: 07 jun. 2015. 
Revista da Faculdade Mineira de Direito | v.20 N.40|272

GIDDENS, A. A Terceira Via: Reflexões sobre o Impasse Político Atual e o Futuro da Social-democracia. Rio de Janeiro: Record,1999.

GRECO, Rogério. Curso de Direito Penal: Parte Geral. 2. ed. Rio de Janeiro: Impetus, 2003, 848 p.

HAMEISTER, Bianca da Rocha; BARBOSA, Paola Vargas; WAGNER, Adriana. Conjugalidade e parentalidade: uma revisão sistemática do efeito spillover. Arq. bras. psicol., Rio de Janeiro, v. 67, n. 2, p. 140-155, 2015. Disponível em <http://pepsic.bvsalud.org/scielo.php?script=sci_arttext\&pid=S1809526 72015000200011\&lng=pt\&nrm=iso $>$. Acesso em: 28 maio 2016.

LEDERACH, John Paul. Conflict Transformation: Clear articulation of the guiding principles by a Pioneer in the Field. Intercourse: Good Books, 2003.

MIRANDA JR., Hélio Cardoso de. Alienação Parental: Comentário Hélio Cardoso Miranda Jr. 2014. Disponível em: <https://www.youtube.com/watch?v=3aOS2YbgYtE $>$. Acesso em: 27 maio 2016.

MIRANDA JR., Hélio Cardoso de. Apontamentos sobre a judicialização dos conflitos familiares. In: Guerra, A.M.C.; Penna, P.D.M.; Soares, S.N..(Org.). Direito e Psicanálise II: o adolescente em foco. 1ed. Curitiba: CRV, 2015, p. 221-230.

MOREIRA, Luciana Maria Reis. Alienação Parental: uma análise dos meios de resolução do conflito para além da Lei n. 12.318/2010. 2013. 114f. Dissertação (Mestrado em Direito) - Pontifícia Universidade Católica de Minas Gerias, Belo Horizonte, 2013. 
Revista da Faculdade Mineira de Direito $\mid$ v.20 N.40|273

PRANIS, Kay. Processo Circulares. Tradução por Tonia Von Acker. São Paulo: Palas Athena, 2010. (Da reflexão à ação).

ROSENBERG, Marshall B. Comunicação Não-Violenta: técnicas para aprimorar relacionamentos pessoais e profissionais. São Paulo: Ágora, 2006.

SANTOS, Boaventura de Sousa. Para uma revolução democrática da justiça.

3 ed. São Paulo: Cortez, 2011. Disponível em: < http://sociologial.dominiotemporario.com/doc/REVOLUCAO_DEMO CRATICA_JUSTICA.pdf $>$. Acesso em: 12 jun. 2016.

SOARES, Laura Cristina Eiras Coelho. Mudanças na conjugalidade repercuções na parentalidade: separação conjugal e guarda compartilhada sob o olhar da psicologia jurídicia. Boletim Interfaces da Psicologia da UFRRJ, Seropédica, v. 2, n. 2, p. 55-69, Dez. 2009. Disponível em: < http://www.ufrrj.br/seminariopsi/2009/boletim2009-2/soares.pdf>. Acesso em: 28 maio 2016.

SOLER, Raúl Calvo. Mapeo de conflictos. Barcelona: Gedisa, 2014.

SOUSA, Analícia Martins de; AMENDOLA, Marcia Ferreira. Falsas denúncias de abuso sexual infantil e Síndrome da Alienação Parental (SAP): distinções e reflexões necessárias. In:

Leila Maria Torraca de Brito. (Org.). Escuta de Crianças e adolescentes: reflexões, sentidos e práticas. 1ed.rio de janeiro: EdUERJ, 2012, v. 1. 